\title{
The Emerging Role of Laparoscopic Liver Resection in the Treatment of Recurrent Hepatocellular Carcinoma: A Systematic Review
}

\author{
NIKOLAOS MACHAIRAS ${ }^{1^{*}}$, DIMITRIOS PAPACONSTANTINOU ${ }^{1 *}$, PARASKEVAS STAMOPOULOS ${ }^{2 *}$, \\ ANASTASIA PRODROMIDOU ${ }^{2}$, ZOE GAROUFALIA $^{2}$, ELEFTHERIOS SPARTALIS $^{2}$, \\ IOANNIS D. KOSTAKIS ${ }^{2}$ and GEORGIOS C. SOTIROPOULOS ${ }^{2}$ \\ ${ }^{1}$ Third Department of Surgery, Attikon University Hospital, Medical School, \\ National and Kapodistrian University of Athens, Athens, Greece; \\ ${ }^{2}$ Second Department of Propaedeutic Surgery, Laiko General Hospital, Medical School, \\ National and Kapodistrian University of Athens, Athens, Greece
}

\begin{abstract}
Background/Aim: Tumor recurrence complicates more than half of patients at 5 years after primary hepatocellular carcinoma (HCC) resection. Repeat open liver resection $(R O L R)$ is the standard procedure for patients eligible for repeat resection, whereas laparoscopic repeat liver resection (RLLR) has been proposed as an alternative approach. The aim of this systematic review is to evaluate studies reporting on outcomes of RLLR for recurrent HCC (rHCC). Materials and Methods: A comprehensive search of the literature was undertaken. Results: A total of 11 studies, 6 non-comparative and 5 comparative (RLLR versus ROLR), which reported outcomes for 165 patients who underwent $R L L R$, were included in our review. RLLRs were associated with reduced blood loss, shorter hospital stay, lower conversion to ROLR and lower morbidity rates. Conclusion: Selected patients with rHCC who undergo RLLR, benefit in terms of short-term outcomes. Larger prospective trials will elucidate the impact of RLLR on long-term outcomes and establish treatment guidelines.
\end{abstract}

Hepatocellular carcinoma (HCC) has risen in frequency and has become the 6th most common neoplasm and the 3rd most frequent cause of cancer death (1). Laparoscopic liver resections (LLR) are currently acknowledged as safe and efficient procedures in the hands of hepatobiliary surgeons

*These Authors contributed equally to this study.

Correspondence to: Nikolaos Machairas, Third Department of Surgery, University Hospital Attikon, Rimini Str. 1, 12462 Athens, Greece. Tel: +30210 5831000, e-mail: nmachair@gmail.com

Key Words: Recurrent hepatocellular carcinoma, laparoscopic open liver resection. with experience in laparoscopic surgery $(2,3)$. Multiple studies and meta-analyses have demonstrated that LLR is a safe and adequate approach for the treatment of HCC (4-9). Moreover, during the years, major resections, resection in challenging liver locations as well as resections in high-risk patient groups including cirrhotic and geriatric patients are increasingly performed with equally outstanding short- and long-term outcomes (10-12).

Tumor recurrence has been demonstrated to be as high as $30-70 \%$ at 5 years after primary $\mathrm{HCC}$ resection and is a critical parameter that limits the overall survival of these patients $(13,14)$. Most centers advocate repeat liver resection when patient status allows it although no established guideline exists as in the case of primary HCC (15). Repeat open liver resection (ROLR) is currently established as a method of choice with acceptable morbidity, mortality and long-term survival rates which have also proved comparable to those of initial liver surgery $(14,16)$. Innovations in the field of laparoscopic surgery and the gradual accrual of experience with laparoscopic techniques have allowed the implementation of laparoscopic surgery in the challenging treatment of recurrent HCC (rHCC). Several studies have been published reporting on results of repeat laparoscopic liver resection (RLLR) in patients with rHCC (17-19).

The objective of the present systematic review was to identify and evaluate available data on the efficacy of RLLR for $\mathrm{rHCC}$.

\section{Materials and Methods}

A comprehensive search of the Medline (PubMed), Embase and Cochrane libraries was undertaken separately by three authors (NM, PS, DP) with the intent to identify non-comparative studies reporting outcomes for LLR in rHCC and studies comparing open surgery to laparoscopic in the setting of rHCC, published in English language. The terms utilized were "recurrent HCC", "recurrent 
hepatocellular carcinoma", "recurrent hepatoma" combined with "laparoscopic liver resection", "laparoscopic hepatectomy", "laparoscopic surgery" and "open surgery", using the Boolean operators AND, OR. The abstracts of the articles yielded by the database search were screened in order to identify observational studies (prospective and retrospective) eligible for inclusion. The eligibility criteria defined by the authors were: English language, full-text articles and studies including a minimum of 3 patients. The exclusion criteria were: studies with incomplete data on patients and procedures, case-reports/reviews/letters and editorials, studies that included patients undergoing procedures other than resection (such as radiofrequency ablation or transplantation), duplicate studies and studies concerning re-resection of metastatic malignancies (colon or elsewhere). All articles deemed eligible for inclusion were subsequently reviewed by all authors and were selected for inclusion in the data analysis. This study was conducted according to PRISMA guidelines (20).

Data extraction and management. Data extracted from eligible studies and were inserted in Excel spreadsheets (Microsoft, Redmond, Washington, USA). Data of interest were patient demographics, information on patient cirrhosis status, status of previous abdominal operation and intra-, peri- and post-operative outcomes.

\section{Results}

The PubMed database search yielded a total of 42 articles. Review of the abstracts identified 15 studies for full-text evaluation. Four studies were excluded under the criteria stated above. Eleven studies were finally included in the present review. Among them, 6 studies were $(17,21-25)$ noncomparative and presented outcomes concerning the efficacy of RLLR for rHCC while 5 studies $(19,26-28)$ were comparative and evaluated the efficacy of ROLR compared with RLLR for rHCC. The PRISMA search flow chart is shown in Figure 1.

Non-comparative studies reporting outcomes of RLLR. A total of 6 non-comparative studies, which comprised 40 patients and reported outcomes for the efficacy and safety of RLLR in the setting of rHCC were included in the present review as shown in Table I. All 6 studies were single-center retrospective and 1 study was a case-series involving 3 patients (25). The aforementioned studies included patients assessed and operated on from the year 2004 to 2017. No studies including patients undergoing re-resection of HCC were identified prior to the year 2004. Among the included patients, 39 underwent resections through a pure laparoscopic technique while one resection was performed using the handassisted technique. Perioperative data are summarized on Table II. The exact type of resection is described for 32 patients. In particular, all laparoscopic resections in the noncomparative studies were minor liver resections, involving 2 or less liver segments. The operative time ranged from 75 to 343 minutes, while blood loss during surgery ranged from 75 to $283 \mathrm{ml}$. Adhesions encountered during surgery were graded using the scale described by Becker et al. (29). The severity of adhesions was graded in 4 of the 6 non-comparative studies. Grade 3 or 4 peritoneal adhesions were encountered in $16 / 29(55 \%)$ of patients. Conversion from laparoscopic to open approach was required in 2 out of 40 cases (5\%). Margin positivity status was reported in 3 out of 6 studies. No case of macroscopic or microscopic positive surgical margin (resection margin $<1 \mathrm{~mm}$ ) was reported among the non-comparative studies. Post-operative morbidity was reported in 5 out of 6 studies and involved 6 patients $(16 \%)$. No post-operative deaths were recorded.

Comparative studies reporting outcome of RLLR vs. ROLR. One prospective and 4 retrospective studies were identified, which compared outcomes from patients who underwent RLLR or ROLR for rHCC (Table I). A total of 267 patients were included. Among them, 125 patients underwent RLLR while the remaining 142 patients underwent ROLR. No significant differences in terms of baseline patient characteristics, including tumor size were reported by the total of the studies. Furthermore, they all demonstrated a significantly lower blood loss rate in favor of RLLR, which resulted in decreased blood transfusion requirements and improved operative outcomes (Table II) (27, 28, 30). Operative time was significantly lower in one study (19) in favor of the laparoscopic approach with the rest of the studies demonstrating non-significant differences. Length of stay was significantly shorter, in 4 out of 5 studies, in the RLLR group (26-28, 30). Postoperative morbidity was evaluated in 4 studies $(26-28,30)$ with 3 of them presenting a significantly decreased morbidity rate in the RLLR group when compared to ROLR. One study additionally demonstrated significantly reduced postoperative pain, earlier return of bowel function and patient mobilization (19). Overall one case of postoperative mortality was reported in a RLLR patient (28).

Long-term outcomes of patients were reported in 3 studies, where disease free survival (DFS) at 1,3 and 5 years were not found to be different among the 2 groups $(19,26,30)$.

\section{Discussion}

The advantages of the laparoscopic approach in the treatment of HCC have been documented in several studies (4-9). Despite the fact that innovations in this field of surgery have come in leaps and bounds during the last decade, many centers worldwide shy away from performing RLLR. In a recently published international survey, the difficulty of LLR was increased by the patients' history of previous liver resection according to $99 \%$ of the survey responders (31). Nonetheless, a substantial number of studies reporting outcomes from small numbers of patients have shown that RLLR is a safe and beneficial alternative to ROLR in the treatment of selected patients with rHCC eligible for resection. 


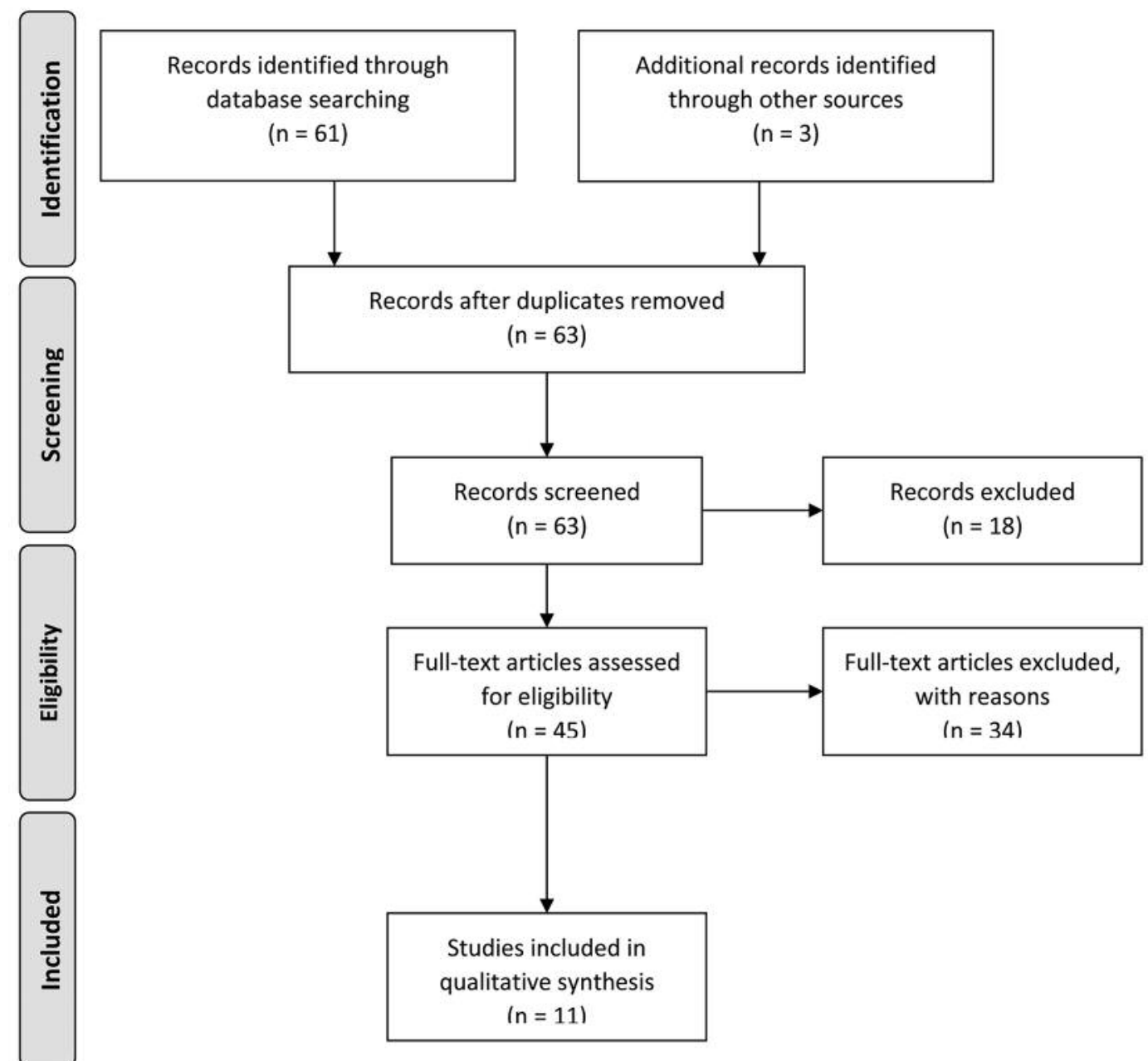

Figure 1. PRISMA flow chart.

The presence of adhesions from previous abdominal surgery constitutes a main concern and an important limitation for the performance of repeat laparoscopic surgery. Collective data from our analysis showed that severe adhesions (grade 3 and 4 ) were present in approximately a third of cases (27/90 cases) as reported in 6 studies. Furthermore, the rate of conversion to ROLR was as low as $4 \%$ which is equivalent to conversion rates reported elsewhere in literature for LLR undertaken for newly diagnosed HCC in virgin abdomens $(32,33)$, suggesting that LLRs although technically complex, are not as cumbersome to patients and surgeons as was initially thought.

One has to take into account, however, that this low cumulative conversion percentage in the present review is derived from retrospective studies with a small number of patients, in centers with substantial experience in laparoscopic liver surgery. This is better reflected on the fact that the median reported blood loss in our data ranged from
$75 \mathrm{ml}$ to $283 \mathrm{ml}$, whereas, published worldwide literature on laparoscopic resections for primary liver malignancies report blood loss of $322 \mathrm{ml}$ to $619 \mathrm{ml}$, depending on the extent of the procedure performed $(32,34)$. Such amount is considerably higher than the one in our review despite the need for adhesiolysis in all cases presented in our analysis. Nonetheless, this result may be attributed to the fact that the vast majority of RLLRs were minor and that complete liver mobilization could have been avoided in many cases. Blood loss during RLLR was found to be significantly lower compared to ROLR in all 5 comparative studies included in our analysis, a result that can further be associated with a reduced need for blood transfusions $(27,30)$ and therefore better short- and long-term outcomes $(35,36)$. Regarding the mean operative time, 4 out of 5 comparative studies did not demonstrate a significantly different operative time, while one prospective study (19) showed a significantly lower operative time for the RLLR. This result, however, should 
Table I. Study characteristics.

\begin{tabular}{|c|c|c|c|c|c|c|c|}
\hline Author & Year & Country & Study type & No of patients & Gender (male) & Age (years) & Type of laparoscopic resection \\
\hline \multicolumn{8}{|c|}{ Non-comparative studies } \\
\hline Belli (21) & 2009 & Italy & Retrospective & 12 & $\mathrm{~N} / \mathrm{a}$ & 69 & Pure Laparoscopic \\
\hline $\mathrm{Hu}(23)$ & 2010 & China & Retrospective & 6 & 5 & 51 & Pure Laparoscopic \\
\hline Ahn (17) & 2011 & Korea & Retrospective & 3 & 3 & 57 & Pure Laparoscopic \\
\hline $\operatorname{Kim}(25)$ & 2013 & Singapore & Retrospective & 3 & 3 & 65 & Pure Laparoscopic \\
\hline Isetani (24) & 2015 & Japan & Retrospective & 8 & $\mathrm{~N} / \mathrm{a}$ & 69 & Pure Laparoscopic \\
\hline Goh (22) & 2016 & Singapore & Retrospective & 8 & 7 & 70 & Pure Laparoscopic, 1 LAH \\
\hline \multicolumn{8}{|c|}{ Comparative studies (RLLR vs. ROLR) } \\
\hline Kanazawa (27) & 2013 & Japan & Retrospective & 20 vs. 20 & 15 vs. 19 & 70 vs. 65 & Pure Laparoscopic \\
\hline Chan (26) & 2014 & China & Retrospective & 11 vs. 22 & N/a & 61 vs. 62 & Pure Laparoscopic \\
\hline Zhang (19) & 2016 & China & Prospective & 31 vs. 33 & 26 vs. 27 & 54 vs. 60 & Pure Laparoscopic \\
\hline Liu (30) & 2017 & China & Retrospective & 30 vs. 30 & 23 vs. 28 & 56 vs. 48 & Pure Laparoscopic \\
\hline Ome (28) & 2018 & Japan & Retrospective & 33 vs. 37 & 26 vs. 27 & 73 vs. 71 & Pure Laparoscopic \\
\hline
\end{tabular}

N/a: Not available; LAH: laparoscopy-assisted hepatectomy; RLLR: repeat laparoscopic liver resection; ROLR: repeat open liver resection.

Table II. Perioperative outcomes.

\begin{tabular}{|c|c|c|c|c|c|c|c|c|}
\hline Author & $\begin{array}{c}\text { Lap } \\
\text { primary } \\
\text { approach }\end{array}$ & $\begin{array}{c}\text { Adhesion } \\
\text { Grade } \\
3-4\end{array}$ & $\begin{array}{l}\text { Operative } \\
\text { time } \\
(\min )\end{array}$ & $\begin{array}{l}\text { Blood } \\
\text { loss } \\
(\mathrm{ml})\end{array}$ & Conversions & $\begin{array}{l}\text { Positive } \\
\text { margins }\end{array}$ & $\begin{array}{c}\text { LoS } \\
\text { (days) }\end{array}$ & Morbidity \\
\hline \multicolumn{9}{|c|}{ Non-comparative studies } \\
\hline Belli (21) & $8 / 12$ & 5 & 75 & N/a & 1 & 0 & $\mathrm{~N} / \mathrm{a}$ & $2(16.6 \%)$ \\
\hline $\mathrm{Hu}(23)$ & $1 / 6$ & 3 & 140 & 283 & 0 & N/a & 5 & $1(16.6 \%)$ \\
\hline Ahn (17) & $2 / 3$ & $\mathrm{~N} / \mathrm{a}$ & $\mathrm{N} / \mathrm{a}$ & $\mathrm{N} / \mathrm{a}$ & 0 & $\mathrm{~N} / \mathrm{a}$ & $\mathrm{N} / \mathrm{a}$ & $\mathrm{N} / \mathrm{a}$ \\
\hline Kim (25) & $3 / 3$ & 1 & 227 & 225 & 0 & 0 & 7 & $1(33 \%)$ \\
\hline Isetani (24) & N/a & 7 & 248 & 75 & 0 & N/a & 11.3 & 0 \\
\hline Goh (22) & $2 / 8$ & $\mathrm{~N} / \mathrm{a}$ & 343 & 200 & 1 & 0 & 3.5 & $1(12.5 \%)$ \\
\hline \multicolumn{9}{|c|}{ Comparative studies (RLLR vs. ROLR) } \\
\hline Kanazawa (27) & $\mathrm{N} / \mathrm{a}$ & $\mathrm{N} / \mathrm{a}$ & $\begin{array}{l}239 \text { vs. } 211 \\
(p=0.6837)\end{array}$ & $\begin{array}{l}78 v s .612 \\
(p<0.001)\end{array}$ & 2 to $\mathrm{LAH}$ & $\mathrm{N} / \mathrm{a}$ & $\begin{array}{c}9 v s .19 \\
(p<0.001)\end{array}$ & $\begin{array}{c}1(5 \%) \text { vs.13 } \\
(65 \%)(p<0.001)\end{array}$ \\
\hline Chan (26) & N/a & $\mathrm{N} / \mathrm{a}$ & $\begin{array}{c}200 \text { vs. } 188 \\
(p=0.939)\end{array}$ & $\begin{array}{c}100 v s .340 \\
(p=0.014)\end{array}$ & 0 & 0 & $\begin{array}{c}6 v s .5 \\
(p=0.831)\end{array}$ & $\begin{array}{c}2(18 \%) v s . \\
1(4.5 \%)(p=0.199)\end{array}$ \\
\hline Zhang (19) & N/a & 5 vs. 7 & $\begin{array}{c}116.7 v s .148 .2 \\
\quad(p=0.031)\end{array}$ & $\begin{array}{c}117.5 v s .265 .9 \\
\quad(p=0.012)\end{array}$ & 0 & 0 & $\begin{array}{l}4.5 v s .6 \\
(p=0.014)\end{array}$ & $\mathrm{N} / \mathrm{a}$ \\
\hline Liu (30) & N/a & $6 v s .10$ & $\begin{array}{c}200.5 \text { vs. } 207.5 \\
\quad(p=0.903)\end{array}$ & $\begin{array}{c}100 v s .400 \\
(p<0.001)\end{array}$ & 3 to ROLR & 0 & $\begin{array}{c}9.5 v s .13 .5 \\
(p<0.001)\end{array}$ & $\begin{array}{c}2(6.6 \%) v s . \\
10(33.3 \%)(p=0.01)\end{array}$ \\
\hline Ome (28) & $\begin{array}{c}12 / 33 v s \\
3 / 37\end{array}$ & $\mathrm{~N} / \mathrm{a}$ & $\begin{array}{c}217 \text { vs. } 222 \\
(p=0.56)\end{array}$ & $\begin{array}{l}30 v s .622 \\
(p<0.001)\end{array}$ & 0 & $\begin{array}{c}3 v s .5 \\
(p=0.406)\end{array}$ & $\begin{array}{l}6.5 v s .9 \\
(p<0.001)\end{array}$ & $\begin{array}{c}2(6.1 \%) v s \\
6(16.2 \%)(p>0.05)\end{array}$ \\
\hline
\end{tabular}

HCC: Hepatocellular carcinoma; LoS: length of stay; N/a: Not available; LAH: laparoscopy-assisted hepatectomy; RLLR: repeat laparoscopic liver resection; ROLR: repeat open liver resection.

be interpreted with caution considering the small sample size and the extensive experience of the reporting centers on laparoscopic hepatectomies.

The oncologic outcome of RLLR in the published studies was adequate, with no positive resection margins, as reported in 6 out of 11 studies. When comparing RLLR and ROLR, morbidity rates were comparable in 2 studies, whereas 2 studies exhibited lower morbidity in the laparoscopic arm $(27,30)$. The length of stay was significantly lower in 4 out of 5 comparative studies; the above results are on par with 
the current consensus that laparoscopic surgery results in an earlier return to normal function. Such effect was not negatively affected by the theoretical disadvantage of extensive adhesiolysis as expected in the setting of previous upper right quadrant interventions. Moreover, these outcomes can be effectively translated into reduced hospitalization costs (37).

A critical issue that needs to be addressed is the partly insufficient data on both the exact approach employed and the extent of the primary resection in the initial primary HCC resection, among the included studies. Overall, 6 noncomparative studies report on the initial surgical approach, thus there is no comparison between patients who underwent open versus laparoscopic surgery as an initial approach. Moreover, as far as the comparative studies are concerned, only Zhang et al. (19) and Ome et al. (28) specified the exact initial approach of the primary resection. In the study by Zhang et al. (19) all patients underwent OLR for the initial HCC and therefore the comparison between the RLLR and ROLR is rational. On the other hand, in the study by Chan et al. (26) the initial approach is described for the RLLR group (11 patients; 6 primary OLR and 5 primary LLR), yet the primary resection approach for the ROLR group is not described. Similarly, with regards to the extent of primary resection only 2 comparative studies provide adequate data $(26,27)$. The lack of this specific information causes great heterogeneity between the groups and suggests a major limitation of our study and is a critical reason why a relevant meta-analysis cannot be performed. Another important limitation of the included studies is that long-term comparative outcomes are sparsely reported. One-year DFS percentages were reported in only two studies $(19,30)$ with results being comparable between the laparoscopic and open groups. The same can be demonstrated for 3-year overall and disease-free survivals (Table II).

\section{Conclusion}

In conclusion, the above results demonstrate that RLLR is a safe and promising approach in the treatment of rHCC in selected patients. Contrary to the popular belief that adhesion formation from previous upper right quadrant surgery might significantly impact negatively perioperative and oncological outcomes, the current study shows no such outcome. Nonetheless such result must be interpreted with caution as one could hypothesize that the included patients are only highly selected with preoperatively deemed easily resectable lesions with/or good underlying liver quality. Regardless, a number of patients with rHCC eligible to undergo reresection operated through the laparoscopic approach benefit significantly in terms of short-term outcomes akin to patients who undergo LLR for primary HCC, while the oncologic adequacy of the procedure is not compromised. Larger and better-designed prospective trials should be actively pursued to further elucidate the impact of RLLR on long-term outcomes and thus establish treatment guidelines.

\section{Conflicts of Interest}

The Authors declare no conflicts of interest.

\section{References}

1 Ferlay J, Shin HR, Bray F, Forman D, Mathers C and Parkin DM: Estimates of worldwide burden of cancer in 2008: GLOBOCAN 2008. Int J Cancer 127: 2893-2917, 2010.

2 Vigano L, Laurent A, Tayar C, Tomatis M, Ponti A and Cherqui D: The learning curve in laparoscopic liver resection: improved feasibility and reproducibility. Ann Surg 250: 772-782, 2009.

3 Buell JF, Cherqui D, Geller DA, O'Rourke N, Iannitti D, Dagher I, Koffron AJ, Thomas M, Gayet B, Han HS, Wakabayashi G, Belli G, Kaneko H, Ker CG, Scatton O, Laurent A, Abdalla EK, Chaudhury P, Dutson E, Gamblin C, D'Angelica M, Nagorney D, Testa G, Labow D, Manas D, Poon RT, Nelson H, Martin R, Clary B, Pinson WC, Martinie J, Vauthey JN, Goldstein R, Roayaie S, Barlet D, Espat J, Abecassis M, Rees M, Fong Y, McMasters KM, Broelsch C, Busuttil R, Belghiti J, Strasberg S and Chari RS: The international position on laparoscopic liver surgery: The Louisville Statement, 2008. Ann Surg 250: 825-830, 2009.

4 Wakabayashi G, Cherqui D, Geller DA, Buell JF, Kaneko H, Han HS, Asbun H, O'Rourke N, Tanabe M, Koffron AJ, Tsung A, Soubrane O, Machado MA, Gayet B, Troisi RI, Pessaux P, Van Dam RM, Scatton O, Abu Hilal M, Belli G, Kwon CH, Edwin B, Choi GH, Aldrighetti LA, Cai X, Cleary S, Chen KH, Schon MR, Sugioka A, Tang CN, Herman P, Pekolj J, Chen XP, Dagher I, Jarnagin W, Yamamoto M, Strong R, Jagannath P, Lo CM, Clavien PA, Kokudo $\mathrm{N}$, Barkun J and Strasberg SM: Recommendations for laparoscopic liver resection: a report from the second international consensus conference held in Morioka. Ann Surg 261: 619-629, 2015.

5 Sposito C, Battiston C, Facciorusso A, Mazzola M, Muscara C, Scotti M, Romito R, Mariani L and Mazzaferro V: Propensity score analysis of outcomes following laparoscopic or open liver resection for hepatocellular carcinoma. Brit J Surg 103: 871-880, 2016.

6 Sotiropoulos GC, Machairas N, Stamopoulos P, Kostakis ID, Dimitroulis D, Mantas D. and Kouraklis G: Laparoscopic versus open liver resection for hepatocellular carcinoma: initial experience in Greece. Ann Gastroenterol 29: 521-529, 2016.

7 Sotiropoulos GC, Prodromidou A, Kostakis ID and Machairas $\mathrm{N}$ : Meta-analysis of laparoscopic vs. open liver resection for hepatocellular carcinoma. Upd Surg 69: 291-311, 2017.

8 Xiong JJ, Altaf K, Javed MA, Huang W, Mukherjee R, Mai G, Sutton R, Liu XB and Hu WM: Meta-analysis of laparoscopic $v s$. open liver resection for hepatocellular carcinoma. World $\mathrm{J}$ Gastroenterol 18: 6657-6668, 2012.

9 Sotiropoulos GC, Prodromidou A and Machairas N: Meta-analysis of laparoscopic $v s$. open liver resection for hepatocellular carcinoma: The European experience. JBUON 22: 1160-1171, 2017.

10 Cheung TT, Dai WC, Tsang SH, Chan AC, Chok KS, Chan SC and Lo CM: Pure Laparoscopic Hepatectomy Versus Open Hepatectomy for Hepatocellular Carcinoma in 110 Patients With Liver Cirrhosis: A Propensity Analysis at a Single Center. Ann Surg 264: 612-620, 2016. 
11 Cipriani F, Fantini C, Ratti F, Lauro R, Tranchart H, Halls M, Scuderi V, Barkhatov L, Edwin B, Troisi RI, Dagher I, Reggiani P, Belli G, Aldrighetti L and Abu Hilal M: Laparoscopic liver resections for hepatocellular carcinoma. Can we extend the surgical indication in cirrhotic patients? Surg Endosc 32: 617626, 2018.

12 Sotiropoulos GC, Machairas N and Kostakis ID: Case Report: Laparoscopic hepatectomy in an elderly patient with major comorbidities. F1000res 6: 1286, 2017.

13 Llovet JM, Schwartz M and Mazzaferro V: Resection and liver transplantation for hepatocellular carcinoma. Sem Liv Dis 25: 181-200, 2005.

14 Zhou Y, Sui C, Li B, Yin Z, Tan Y, Yang J and Liu Z: Repeat hepatectomy for recurrent hepatocellular carcinoma: a local experience and a systematic review. World J Surg Oncol 8: 55, 2010.

15 Jelic S and Sotiropoulos GC: Hepatocellular carcinoma: ESMO Clinical Practice Guidelines for diagnosis, treatment and followup. Ann Oncol 21: v59-v64, 2010.

16 Minagawa M, Makuuchi M, Takayama $\mathrm{T}$ and Kokudo N: Selection criteria for repeat hepatectomy in patients with recurrent hepatocellular carcinoma. Ann Surg 238: 703-710, 2003.

17 Ahn KS, Han HS, Yoon YS, Cho JY and Kim JH: Laparoscopic liver resection in patients with a history of upper abdominal surgery. World J Surg 35: 1333-1339, 2011.

18 Shelat VG, Serin K, Samim M, Besselink MG, Al Saati H, Gioia PD, Pearce NW and Abu Hilal M: Outcomes of repeat laparoscopic liver resection compared to the primary resection. World J Surg 38: 3175-3180, 2014.

19 Zhang J, Zhou ZG, Huang ZX, Yang KL, Chen JC, Chen JB, Xu L, Chen MS and Zhang YJ: Prospective, single-center cohort study analyzing the efficacy of complete laparoscopic resection on recurrent hepatocellular carcinoma. Chin J cancer 35: 25, 2016.

20 Moher D, Liberati A, Tetzlaff J, Altman DG and Group P: Preferred reporting items for systematic reviews and metaanalyses: the PRISMA statement. PLoS med 6: e1000097, 2009.

21 Belli G, Cioffi L, Fantini C, D'Agostino A, Russo G, Limongelli $\mathrm{P}$ and Belli A: Laparoscopic redo surgery for recurrent hepatocellular carcinoma in cirrhotic patients: feasibility, safety, and results. Surg Endosc 23: 1807-1811, 2009.

22 Goh BKP, Teo JY, Chan CY, Lee SY, Cheow PC and Chung AYF: Laparoscopic repeat liver resection for recurrent hepatocellular carcinoma. ANZ J Surg 87: E143-e146, 2017.

$23 \mathrm{Hu} \mathrm{M}$, Zhao G, Xu D and Liu R: Laparoscopic repeat resection of recurrent hepatocellular carcinoma. World J Surg 35: 648-655, 2011.

24 Isetani M, Morise Z, Kawabe N, Tomishige H, Nagata H, Kawase $\mathbf{J}$ and Arakawa S: Pure laparoscopic hepatectomy as repeat surgery and repeat hepatectomy. World J Gastroenterol 21: 961-968, 2015.

25 Kim G, Lau AC and Chang SK: Single-incision laparoscopic hepatic resection in patients with previous hepatic resections: a mini case series. Asian J Endosc Surg 7: 63-66, 2014.

26 Chan AC, Poon RT, Chok KS, Cheung TT, Chan SC and Lo CM: Feasibility of laparoscopic re-resection for patients with recurrent hepatocellular carcinoma. World J of Surg 38: 11411146, 2014.

27 Kanazawa A, Tsukamoto T, Shimizu S, Kodai S, Yamamoto S, Yamazoe S, Ohira $G$ and Nakajima T: Laparoscopic liver resection for treating recurrent hepatocellular carcinoma. J Hepatobiliary Pancreat Sci 20: 512-517, 2013.
28 Ome Y, Hashida K, Yokota M, Nagahisa Y, Yamaguchi K, Okabe $\mathrm{M}$ and Kawamoto $\mathrm{K}$ : The feasibility and efficacy of pure laparoscopic repeat hepatectomy. Surg Endosc, 2018. doi: 10.1007/s00464-018-6066-7. [Epub ahead of print]

29 Becker JM, Dayton MT, Fazio VW, Beck DE, Stryker SJ, Wexner SD, Wolff BG, Roberts PL, Smith LE, Sweeney SA and Moore M: Prevention of postoperative abdominal adhesions by a sodium hyaluronate-based bioresorbable membrane: a prospective, randomized, double-blind multicenter study. J Am Coll Surg 183: 297-306, 1996.

30 Liu K, Chen Y, Wu X, Huang Z, Lin Z, Jiang J, Tan W and Zhang L: Laparoscopic liver re-resection is feasible for patients with posthepatectomy hepatocellular carcinoma recurrence: a propensity score matching study. Surg Endosc 31: 4790-4798, 2017.

31 Halls MC, Cherqui D, Taylor MA, Primrose JN, Abu Hilal M, Abu Hilal M, Aldrighetti L, Al Saati H, Alseidi A, Aroori S, Belli G, Besselink M, Edwin B, D'Hondt M, Dagher I, Dejong C, Geller D, Hamady Z, Hamoui M, Isaksson B, Ivanecz A, Le Roux G, Lesurtel M, O'Rouke N, Prasad R, Prieto Calvo M, Reddy S, Rotellar F, Santoyo J, Soonawalla Z, Soubrane O, Stavrou G, Subar D, Sutcliffe R, Tanis P, Troisi R, Van Dam R, Wakabayashi $G$ and White $S$ : Are the current difficulty scores for laparoscopic liver surgery telling the whole story? An international survey and recommendations for the future. HPB 20: 231-236, 2018

32 Ciria R, Cherqui D, Geller DA, Briceno J and Wakabayashi G: Comparative short-term benefits of laparoscopic liver resection: 9000 cases and climbing. Ann Surg 263: 761-777, 2016.

33 Troisi RI, Montalti R, Van Limmen JG, Cavaniglia D, Reyntjens K, Rogiers X and De Hemptinne B: Risk factors and management of conversions to an open approach in laparoscopic liver resection: analysis of 265 consecutive cases. HPB 16: 75-82, 2014.

34 Liu H, Wang D, Yu Y, Ren H and Jiang T: Meta-analysis of efficacy of laparoscopic hepatectomy versus open hepatectomy for hepatocarcinoma. J Cancer Res Ther 13: 849-855, 2017.

35 Fan ST, Ng IO, Poon RT, Lo CM, Liu CL and Wong J: Hepatectomy for hepatocellular carcinoma: the surgeon's role in long-term survival. Arch Surg (Chicago, Ill: 1960) 134: 11241130, 1999.

36 Makino Y, Yamanoi A, Kimoto T, El-Assal ON, Kohno H and Nagasue N: The influence of perioperative blood transfusion on intrahepatic recurrence after curative resection of hepatocellular carcinoma. Am J Gastroenterol 95: 1294, 2000.

37 Cleary SP, Han HS, Yamamoto M, Wakabayashi G and Asbun HJ: The comparative costs of laparoscopic and open liver resection: a report for the 2nd International Consensus Conference on Laparoscopic Liver Resection. Surg Endosc 30: 4691-4696, 2016. 